\title{
Microbial Community Behaviour in The Rhizosphere of Kilemo (Litsea cubeba L. Pers) After Pruning
}

\author{
Enny Widyati
}

Forestry Research and Development Agency, Jl. Gunung Batu No. 5 Bogor, Indonesia 16610

Received Agustus 23, 2016/Accepted October 20, 2016

\begin{abstract}
Pruning is a removing some parts of the tree canopy, either for improving tree shape or increasing shoot productivity. It can be implemented in yield management of commodities that are harvested its shoot biomass, such as tea or kilemo. This activity interferes plant growth, hence affect root secretion. Consequently, it alters soil microbe populations in the rhizosphere. This paper observes the impacts of pruning on fluctuation of root exudates (soil sugar) and rhizosphere communities of 2-years-old kilemo (Litsea cubeba L. Pers.). Tree samples were pruned by removing shoots above the lowest branches. A month after cutting, trees fertilized using 3 types of fertilizers: leaf, NPK, and organic fertilizer. As a control, there were non-fertilized treated trees. To observe the root exudation and microbes populations, $0-20 \mathrm{~cm}$ depth of soil at rhizospheres were collected from $10^{\text {th }}, 30^{\text {th }}$, $60^{\text {th }}$, and $90^{\text {th }}$ day after pruning. Samples were further analyzed for observing the amount of soil-sugar and microbes population, such as $N$ fixer, cellulose degrader, and phosphate solubilizer. Results show that kilemo root drastically decreased their sugar

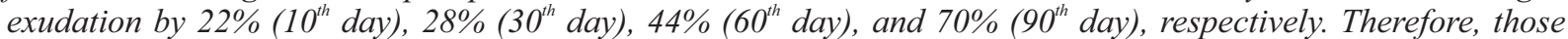
populations were significantly depleted. Rhizosphere sugar can be improved by fertilization, however, the augmentation did not enhance the rhizosphere communities.
\end{abstract}

Keywords: cellulose-degrader, phosphate-solubilizer, pruning, rhizosphere, root exudates

*Correspondence author, email:enny_widyati@yahoo.com;ph: +62-2518633234;fax: +62 2518638111

\section{Introduction}

Kilemo, with market name, may chang (Litsea cubeba L. Pers) is a tree or shrub 5-12 m height in the Lauraceae family. This species is native to China, Indonesia, Taiwan, and other parts of Southeast Asia. It produces a fruit which is processed for its lemony essential oil (Heyne 1987). The oil can also be extracted from the leaf, but this is considered to be lower in quality (Agrawal et al. 2011). To improve leaves productivity can be done by the pruning application. Recognized as coppice system, can be adopted in yield management of its biomass productivity. Since, by this system farmers can harvest frequently from once of plantation hence manage their sustainability in nature.

In silviculture system, pruning is conducted to improve wood quality (log), by removing unproductive branches. This elimination is intended for saving growth energy (Alvarez et al. 2013). Alvarez et al. (2013) reported that pruning application on Prosopsis juliflora increased their rate of photosynthesis. Pruning can also be applied to plants that harvested their leaves such as tea, kilemo, etc, for increasing leaf productivity.

Pruning is presumed not only giving positive but also sometimes negative impacts on plants growth, depending on the proportions of removed plant segments. When cropping is applied only on a small part of branches which obtain less light, it will reduce competition among branches, therefore will optimize photosynthesis process. On the other hand, if cutting is conducted on large parties of trees canopy it will lessen photosynthesis area. Diminishing photosynthesis area is assumed will decrease exudates secreting to rhizosphere, substances which determine the microbe communities in the rhizosphere.

It is not debatable that among plants and soil microbes have a close relationship. The area in soil where a part of plants (root) interacts directly with soil microbes is defined as rhizosphere. Lines-Kelly (2005) stated that rhizosphere is the zone of soil surrounding a plant root where soil biology and chemistry processes are influenced by the root. Chemicals and biologicals activities in the rhizosphere are essential to supply available nutrients for plants. Both chemical compounds released by plant roots and enzymes produced by soil microbes, are intensively determine those processes.

Rhizosphere zone is the busiest area in soil, where chemical compounds and elements are interchangeable. Root hairs play an important role in absorbing nutrients needed for plants growth. Soil microbes, on the other hand, accomplish biological activities for facilitating nutrients availability in the rhizosphere. In return, roots release exudates that critical for microbial metabolisms. The root secretions include amino acids, organic acids, carbohydrates, sugars, vitamins, mucilage, and proteins. These substances 
act as messengers that stimulate biological and physical interactions between roots and soil organisms. They modify biochemical and physical properties of the rhizosphere and contribute to root growth and plant survival (Lines-Kelly 2005).

Plants release $15-40 \%$ of photosynthesis yield into the soil through exudation process. Among the numerous components secreted by roots, carbohydrates (sugars, polysaccharides, etc) are the most abundant (Hutsch et al. 2002). Sugars account for $46-52 \%$ in the exudates of wheat, alfalfa and pea plants roots (Hutsch et al. 2002). The dominant soil sugars are glucose, fructose, galactose, arabinose, maltose, raffinose, rhamnose, sucrose, and xylose (Grayston \& Campbell 1996). Furthermore, sugars are the most abundant organic compounds in the biosphere (Gunina \& Kuzyakov 2015).

Root exudates facilitate colonization of specific fungi and bacteria in root environment (Sørensen 1997) that determine population size and composition of soil microbe communities. Those communities associated with plants in the rhizosphere decide soil volume which can be influenced by root. Rhizosphere zone is about $1 \mathrm{~mm}$ wide but has no distinct edge (Lines-Kelly 2005), most plant rhizospheres can give impact to microbe communities and it can reach up to $10 \mathrm{~cm}$ distance (Gregory 2006). The size and composition of rhizosphere are crucial to plants health and fertility (Sørensen 1997).

Rhizosphere-inhabited microbes play important roles in nutrients cycling through organic matter decomposition and mineralization activities. They are key actors determining functions and sustainability of root ecosystem. Since those microbes are the main producer of enzymes for decomposing complex organic matter to simple elements. These elements can be readily absorbed by plant roots (Kandeler et al. 1996). On the other hand, when soils are in imbalance situations, such as, either nutrients deficiency or toxic, microbes will act in chelation, solubilization, oxidation or reduction (Marschner et al. 2011), therefore minerals are available and sufficient to plants. For instance, phosphor $(\mathrm{P})$ is the most difficult in being sufficient for plants and microbes in the soil. Both plants and microbes increase $\mathrm{P}$ solubility by secreting protons, $\mathrm{OH}^{-}, \mathrm{CO}_{2}$ or/and organic acid anions such as citrate, malate, and oxalate (Hinsinger 2001). Whereas, microbes in the rhizosphere release several enzymes, particularly phosphatase, for mineralizing organic $\mathrm{P}$ (Zhang et al. 2010).

Application of fertilizers is one of the ways to improve shoot productivity after pruning. Fertilizers are divided into inorganic and organic ones based on their chemical forms. Inorganic fertilizers application will increase the concentrations of available macro-nutrients in the rhizosphere (Miah et al. 1998), such as nitrogen, phosphorus, and potassium that play a crucial role in plant growth and yield. Whereas organic application, accelerate the mineralization of $\mathrm{N}$ through the stimulation of the microbial activity, as well as the improvement of rhizosphere volume itself by enhancing the root development (Moritsuka et al. 2013). However, little information is available on the effect of pruning and application of fertilizers to the fluctuation of soil exudates and dynamic of community in the rhizosphere.

Therefore, this paper observes the impact of pruning on the dynamics of kilemo root exudates and the population of nitrogen-fixer bacteria (NFB), cellulose-degrading microbes (CDM), and phosphate solubilizing microbes (PSM), influences of fertilizer application after pruning, as well.

\section{Methods}

Pruning Study was conducted on 2-year age kilemo plantation. Among 200 selected trees, half of that populations were pruned utilizing a saw, the rest half (100 trees) were not pruned, as a control. Fragment of trees that be removed was all upper part of the lowest branches. After being cut, each of the opened stumps was wrapped with a plastic bag to prevent the remnants from over evaporation, for 2 weeks.

Fertilizer application Fertilizers were applied after stumps producing coppice in $8-15 \mathrm{~cm}$ length, averagely. It was assumpted that, in those conditions, shoots have been able to process photosynthesis. In this study, those size of coppices were reached after 30 days of pruning. Fertilizers applied based on the recommended dosage available at each label of a package, namely: NPK (300 $\mathrm{g}$ tree ${ }^{-1}$ ); leaf fertilizer (LF)

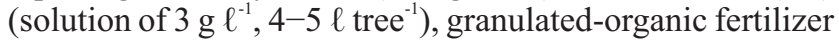
(GOF) (500 $\mathrm{g}_{\text {tree }}{ }^{-1}$ ), and non-fertilized as a control. All fertilizers were applied to both pruned and non-pruned trees. NPK and GOF were applied by burying them around root zone as conversion area of the canopy. While LF was given by spraying the solution onto upper and lower surface of the leaves. Fertilizer experiment was designed in randomizedcompleted design.

Soil sampling and buds calculation Accessing of root exudate and microbes community was initially conducted by collecting soil samples in the rhizosphere at the $50-100 \mathrm{~cm}$ radius from the stemps, with $0-20 \mathrm{~cm}$ depth. For each treatment will be randomized selected 15 of 25 trees. Soil samples were collected after compositing (Pansu \& Gautheyrou 2003) of 3 sampling points at each individual tree. Soil sampling for observing root exudate was conducted at the $10^{\text {th }}, 30^{\text {th }}, 60^{\text {th }}, 90^{\text {th }}$, and $120^{\text {th }}$ days after pruning. Whereas, samples for calculating rhizosphere communities were accomplished at the $30^{\text {th }}, 60^{\text {th }}, 90^{\text {th }}$, and $120^{\text {th }}$ days after pruning. Buds at the size $>5 \mathrm{~cm}$ length were calculated at the $15^{\text {th }}, 30^{\text {th }}, 60^{\text {th }}, 90^{\text {th }}$, and $120^{\text {th }}$ days after pruning.

Soil analysis To measure root exudates soil samples were analyzed used high-performance liquid chromatography (HPLC) method to examine soil sugars amount (Pansu \& Gautheyrou 2003). Since this compound is the most dominant of root exudate and the main food source for soil microbes in the rhizosphere.

Calculating the rhizosphere communities were observed by a plate count method for CDM and PSM, and in most probable number (MPN) method for NFB (Elsas et al. 2006). A number of $10 \mathrm{~g}$ of each soil sample, firstly, was diluted into $90 \mathrm{~m} \ell$ of physiological solution $(\mathrm{NaCl} 0.85 \mathrm{~g}$ in $100 \mathrm{~m} \ell$ aqua dest $=0.85 \%$ ), then stirred well. Afterward, 1 $\mathrm{m} \ell$ of that soil solution will further dilute into $9 \mathrm{~m} \ell$ of aqua dest $\left(10^{-1}\right)$, dilutions were continued until obtained the $10^{-5}$ solution. The last 3 solution levels were further cultured in 
media carboxy methyl cellulose agar for cellulose-degrading microbes (CDM) and pikouvskaya agar for phosphate solubilizing microbes (PSM), media brilliant green lactose bile broth for the nitrogen fixer bacteria (NFB). A number of colonies will be calculated in the 7 days after isolation.

Data analysis Data collected were analyzed statistically to identify the influence of treatments through the analysis of variance (Anova). Once treatments were recognized gave impact than further analyzed to distinguish the significance influence of each treatment using Duncan's multiple range test with the level of confidence by $95 \%$. Depletion activities due to pruning measured with the formulation as shown in Equation [1].

Reduction of exudation $=\frac{(\text { non pruned }- \text { pruned })}{\text { non pruned }} \times 100 \%$

Effectivity of treatments were calculated through the Equation [2].

Effectivity of fertalizer $=\frac{(\text { Fertalizer treatment }- \text { non fertalizing })}{\text { non fertalizing }} \times 100 \%$ [2]

\section{Results and Discussion}

The impact of pruning to root exudation in the rhizosphere Pruning activities drastically reduced the productivity of soil sugar released to the root zone (Figure 1). By the day $10^{\text {th }}$ after the pruning content of soil sugar in the rhizosphere reduced by $22 \%$ compare to unpruned plants.

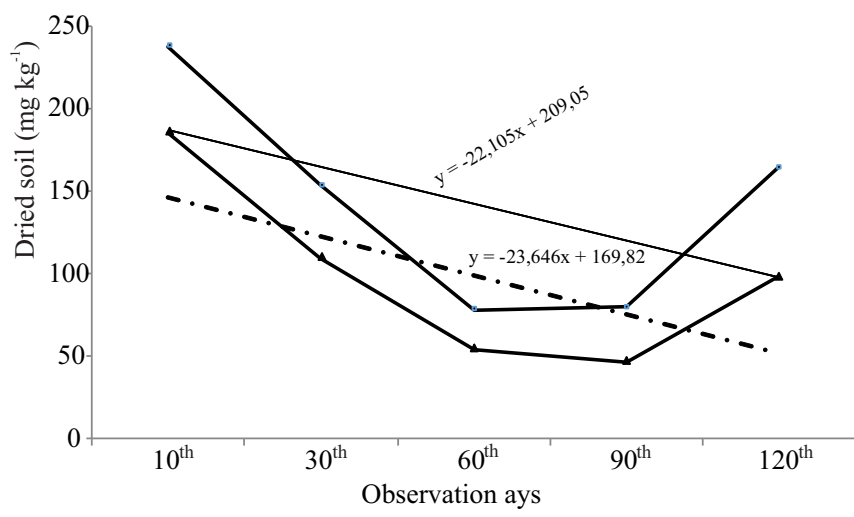

Figure 1 Impact of pruning on a total of sugar in the rhizosphere. Non pruned $(\longrightarrow)$, pruned $(\longrightarrow)$, linear (non pruned) $(-)$, linear (pruned) $(-\cdot-)$.
The decrement tended to get higher in line with the time of observations, which were $29 \%, 31 \%, 41 \%$, and $40 \%$, respectively, at the $30^{\text {th }}, 60^{\text {th }}, 90^{\text {th }}$, and $120^{\text {th }}$ day after pruning (Table 1).

In this study pruning apparently gave negative impact to the root performance, the primarily amount of soil sugar released by roots to the rhizosphere was drastically reduced (Figure 1). Those reductions were supposed to be caused by removing $>30 \%$ of tree canopies when they were pruned. This huge elimination drastically diminished area for their photosynthesis. Therefore, carbohydrates, for example, soil sugars, as the products of that process were decreased. Referring to Neumann (2007), root exudates productivity (both kinds and amount), was strongly determined by kind of species, plant age, plant health, soil fertility, and environment status. According to that opinion, removing a large portion of the canopy was not only decrease the photosynthesis arena but also can be an environment interruption to plants, hence declined root exudation (Figure 1).

Figure 1 also illustrated that production of soil sugar also declined to correspond to the time of observations, either on the pruned trees or the non-treated ones. This was presumed related to rainfall condition at the field. Since pruning must be conducted at moderate rainfall for avoiding rot or drought of remnant stemps. So, in this study, those were conducted in March. The further month's rainfall were getting lower, that soil sugar production decreased, as well. This data was also corresponding to Neumann (2007) that one of the determinant factors in producing soil sugar is environment situation (involved rainfall). It is reported that the change in precipitation is likely going to affect soil moisture, hence give impact to the intensity of soil drying-rewetting cycles, and it could define root exudation (Gorissen et al. 2004). The production of root exudates (involved soil sugar) was increased, in line with augmentation of soil moisture content (Dijkstra \& Cheng 2007), and vise versa. When soil moisture reduced, it causes a decrease in enzyme activity (Sardans \& Penuelas 2005), and it declined the thickness of water films on soil surfaces and therefore the rate of diffusion of substrates to microbes (Stark \& Firestone 1995), hence reduced their population in the soil.

In this research, soil sugar content, both pruned and nonpruned were decreased in line with time. Trend of declining was similar between pruned $(\mathrm{Y}=-23.65 \mathrm{X}+169.8)$ and non prunned ( $\mathrm{Y}=-22.11 \mathrm{X}+209.1)$ (Figure 1). However, as illustrated in Figure 1 that declining of pruned trees is greater in a significant difference than non-pruned treatment

Table 1 Depletion of percentage of total soil sugar in the rhizosphere due to pruning

\begin{tabular}{lccccc}
\hline \multicolumn{1}{c}{ Treatments } & Day 10 & Day 30 & Day 60 & Day 90 & Day 120 \\
\hline Non pruned $(\mathrm{ppm})$ & $237.7^{\mathrm{a}}$ & $153.7^{\mathrm{a}}$ & $78.4^{\mathrm{a}}$ & $79.6^{\mathrm{a}}$ & $164.2^{\mathrm{a}^{*}}$ \\
Pruned (ppm) & $185.4^{\mathrm{b}}$ & $109.5^{\mathrm{b}}$ & $54.3^{\mathrm{b}}$ & $46.8^{\mathrm{b}}$ & $98.5^{\mathrm{b}}$ \\
Persentage of reduction (\%) & 22 & 29 & 31 & 41 & 40 \\
\hline
\end{tabular}

*Mean of the same category followed by different letters are significantly different at 0.05 level of probability 
(Table 2), it is assumed that pruning is given more impact rather than precipitation to deplete root exudate production in soil.

The impact of fertilizer after pruning to root exudation in the rhizosphere Table 2 indicated that amount of soil rhizosphere can be improved by fertilizer application. In this experiment, all kind of fertilizers were significantly increased the amount of soil sugar in the rhizosphere, either pruned or non-cut plants. The positive impact of fertilizers can be observed until the day $120^{\text {th }}$.

Figure 2 illustrated that at the $90^{\text {th }}$ day after pruning plants have the biggest amount of number buds that similar with Table 2, when at the same time have the biggest content of soil sugar. Figure 2 also demonstrated that fertilizer treatments also enhanced the generation of new buds on the pruned trees.

All kinds of fertilizers advanced the soil sugar released by root plants to the rhizosphere both in pruned and non-treated plants (Tabel 2). It can be understood that fertilizers application improved nutrients availability to the plants. In consequence, it expanded plants metabolisms (especially photosynthesis process) hence increased soil sugar released to the rhizosphere. Table 2 demonstrated that soil sugar content in the rhizosphere of non-disturbed plants was better than in the pruned trees even though were given fertilizers. This was assumed that pruning reduced area of photosynthesis until the $120^{\text {th }}$ day of observation. This disturbance impacts can be lessened by fertilizers, however, have not improved soil sugar produced up to 3 months of fertilizing. Since, fluctuation of soil sugar released by roots at the pruned trees rhizosphere were indicated have a strong correlation to the dynamic of new buds growth (Figure 2 ).

Table 3 demonstrated that the best enhancement was observed at the $90^{\text {th }}$ day after pruning $\left(60^{\text {th }}\right.$ day after fertilizer application). At that time, NPK fertilizer increased soil sugar content by $508 \%$ on the pruned plants higher than the nonshavedone $(347 \%)$. The least root exudate enhancement were given by application of leaf fertilizers $(267 \%$ and $184 \%$ ) on the pruned and non-treated, respectively. Organic fertilizer, on the other hand, was recognized as the most effective and consistent in enhancing root exudation.

Tabel 3 indicated that fertilizers improved root exudation of kilemo. The highest enhancement was given by organic fertilizer. The highest concentration of soil sugar at rhizosphere resulted of this fertilizer was assumed, not only come from root secretion but also from soil microbes activities in decomposing the organic matter. This treatment

Table 2 Impact of fertilizers on concentration of soil sugar ( $\mathrm{ppm})$ in the rhizosphere

\begin{tabular}{lcccccc}
\hline \multirow{2}{*}{ Treatments } & \multicolumn{3}{c}{ Non pruned } & \multicolumn{3}{c}{ Pruned } \\
\cline { 2 - 7 } & Day 60 & Day 90 & Day 120 & Day 60 & Day 90 & Day 120 \\
\hline Control & $78.4^{\mathrm{d}}$ & $79.6^{\mathrm{d}}$ & $83.4^{\mathrm{d}}$ & $54.3^{\mathrm{c}}$ & $46.8^{\mathrm{d}}$ & $59.6^{\mathrm{c}}{ }^{\mathrm{c}}$ \\
Leaf fertilizer & $169.7^{\mathrm{c}}$ & $226.4^{\mathrm{c}}$ & $179.6^{\mathrm{c}}$ & $141.1^{\mathrm{b}}$ & $171.8^{\mathrm{c}}$ & $164.8^{\mathrm{b}}$ \\
NPK & $213.5^{\mathrm{b}}$ & $355.7^{\mathrm{b}}$ & $288.1^{\mathrm{b}}$ & $195.9^{\mathrm{a}}$ & $284.2^{\mathrm{b}}$ & $184.3^{\mathrm{b}}$ \\
Organic fertilizer & $293.3^{\mathrm{a}}$ & $561.8^{\mathrm{a}}$ & $\mathbf{3 9 8 . 6}^{\mathrm{a}}$ & $192.3^{\mathrm{a}}$ & $494.6^{\mathrm{a}}$ & $\mathbf{3 9 9 . 8}^{\mathrm{a}}$ \\
\hline
\end{tabular}

"Mean of the same category followed by different letters are significantly different at 0.05 level of probability

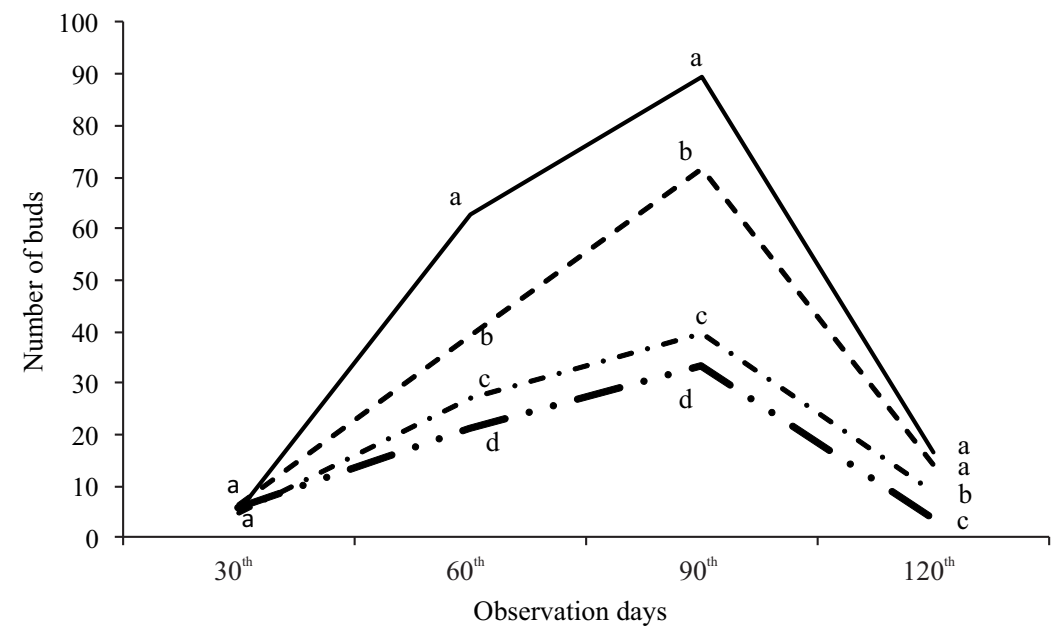

Figure 2 Impact of fertilizers after pruning on new buds appearance. Contol ( $-\bullet)$, leaf $(-\cdots-)$, NPK $\left(-\frac{}{-}\right)$, organic (- - ) 
improved the total soil sugar 6 times fold $(606 \%)$ at the $90^{\text {th }}$ day on the non-cropped trees. Whereas on the pruned trees, this fertilizer increased almost 10 times fold (957\%) compared to the non-fertilized plants. Enhancement of root exudation on pruned trees was much better than the nontreated. Pruned trees have a higher content of soil sugar, because the substance measured in this study was barely sugar which was released to the root zones, otherwise that one used for plants growth. It is assumed that "disturbed" plants need more energy to manage their rhizosphere. It is similar to human life, when people in a stress situation they will spend more energy for healing and others uncalculated.

At the early stages, NPK fertilizer gave the best impact on the development of new buds. Since NPK is the inorganic fertilizer which is fastly available to the root plants. Organic fertilizer, in contrast, is the slowly available to plants root as they need degradation process. The better impact of organic fertilizers began improved at the day $120^{\text {th }}$ after pruning. While leaf fertilizer, was recognized as the least influence on the buds appearance. As this kind of leaf were applied in solution by spraying directly on the leaves on the same day (day $30^{\text {th }}$ ) with another kind of fertilizers. At that day all pruned trees only have fewer leaves so volume that can be absorbed by leaf surfaces were limited.

Impacts of pruning on microbes population in the rhizosphere Population of $\mathrm{N}$-fixer bacteria, P-solubilizer, and cellulose degrader were displayed in Figure 3. All soil microbes in the rhizosphere of pruned trees populations were much lower than those in the non-disturbed plants at all days of observations. In this study, soil microbes population in kilemo rhizosphere diminished due to pruning activities. This depletion was assumed because of declining of total soil sugar secreted by root plants (Figure 1) as a result of canopy cropping. Since soil sugar is the major carbon (food) and energy source for rhizosphere communities associated with root plants. Thus understandable that, limited carbon source in the root zone will inhibit soil microbe population. Comparison of factors limiting bacterial growth in different (Berg et al. 2002) described that rhizosphere community structures were determined by carbon source availability which control the growth and activity of soil microbes. Root exudates were low-molecule-weight compounds afterward easily decomposed by soil microbes, such as soil sugars (Demoling et al. 2007).

This study was consistent with an experiment conducted by Kadiata et al. (1998) on pruned 16 months age Albizia lebbeck and Leucaena leucochepala. Pruning action on those plants depleted $30-38 \%$ of the $\mathrm{N}$-fixer bacteria (rhizobia) population which be inoculated onto their roots compared to the one non pruned (control). As a result, fixed$\mathrm{N}$ content in their tissues reduced by $66-84 \%$ lower than the control.

In this study, the most affected by pruning was a population of the P-solubilizing microbes (Figure $3 \mathrm{c}$ ). That is corresponding to Marschner et al. (2011) that, soil microbes in the plant's rhizosphere not only need root exudates supply from the plants but also compete with plants in nutrients acquisition, particularly $\mathrm{P}$ and Fe. Logically, plants need to save their available $\mathrm{P}$ to survive in the stress condition, in this experiment was because of pruning. Marschner et al. (2011) further explicated that in $\mathrm{P}$ absorption, microbes were more aggressive than root plants. Plants only competent adsorb $\mathrm{P}$ in ion forms, otherwise, microbes capable of utilizing many kind forms of $\mathrm{P}$. Microbes can release $\mathrm{P}$ bond in a soil complex, as well as decompose organic $\mathrm{P}$ compounds from plant and animal residues. On the other hand, they also proficient to immobilize available $\mathrm{P}$ into biomass (and will re-decompose fastly) before being reached by root plants (George et al. 2009).

Depletion of rhizosphere population in this study was presumed as the reaction of plants to alleviate competitors in their root zone. As microbes strongly depend on their carbon supply from root exudates, when the production process was limited by pruning, let their population abundantly in the rhizosphere will be a burden to the plants. Therefore, for exudates efficiency, roots have to limit the size of rhizosphere community.

Jones and Darrah (1994) explained that plants have several mechanisms in reducing soil community magnitude in their root zones. Primarily, plants decline their root exudates productivity. In this study, plants had a limited area for photosynthesis hence they need to produce root exudates efficiently. Alternatively, plants recaptured root exudates that have been released to the rhizosphere. Both mechanisms caused a deficiency carbon source in the rhizosphere, accordingly soil microbes population were diminished.

Weiskopf et al. (2006) demonstrated in what manner white lupin peas (Lupinus albus L) decreased their rhizosphere communities for dealing with disturbance. Firstly, plants released protons and created an acidic environment in their rhizosphere. Microbes are sensitive to $\mathrm{pH}$ flux in the environment, as a result, their population will be limited. The second mechanism was, roots released phenolic compounds to the rhizosphere, afterward enhanced fungi form spores. Spore is a dormant phase hence root exudates in the rhizosphere will be efficiently utilized by soil

Table 3 Efficiency of fertilizer treatments on root exudation (\%)

\begin{tabular}{|c|c|c|c|c|c|c|}
\hline \multirow{2}{*}{ Treatments } & \multicolumn{3}{|c|}{ Non pruned } & \multicolumn{3}{|c|}{ Pruned } \\
\hline & Day 60 & Day 90 & Day 120 & Day 60 & Day 90 & Day 120 \\
\hline Leaf fertilizer & $116^{\mathrm{c}}$ & $184^{\mathrm{c}}$ & $115^{\mathrm{c}}$ & $160^{\mathrm{b}}$ & $267^{c *}$ & $177^{b}$ \\
\hline NPK & $172^{\mathrm{b}}$ & $347^{b}$ & $254^{\mathrm{b}}$ & $261^{\mathrm{a}}$ & $508^{b}$ & $209^{b}$ \\
\hline $\begin{array}{l}\text { Organic } \\
\text { fertilizer }\end{array}$ & $274^{\mathrm{a}}$ & $606^{\mathrm{a}}$ & $378^{a}$ & $254^{\mathrm{a}}$ & $957^{\mathrm{a}}$ & $571^{\mathrm{a}}$ \\
\hline
\end{tabular}



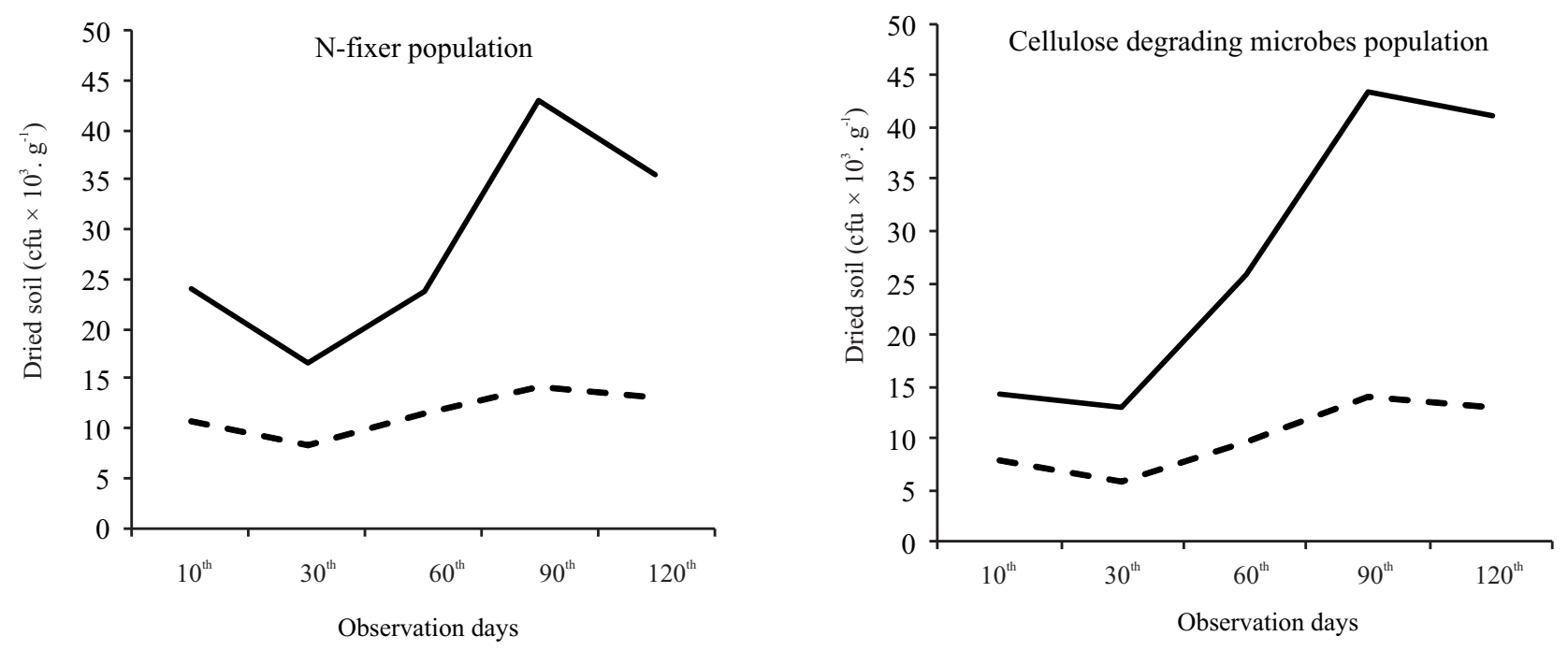

Phosphate Solubilizing Microbes Population

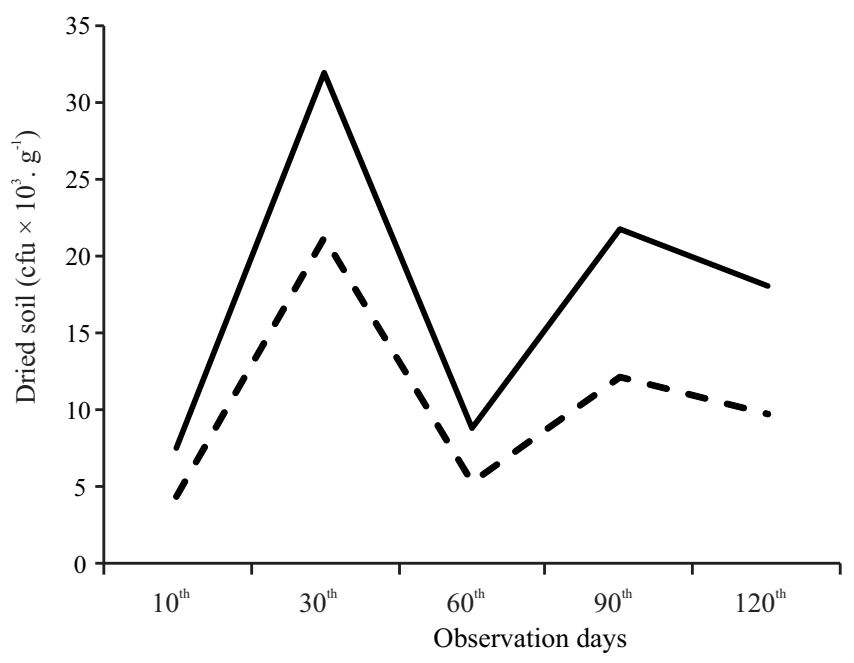

Figure 3 Impacts of pruning on the N-fixer, cellulose degrader and phosphate solubilizer population in the kilemo rhizosphere (CFU: colony forming units). Non prune $(\longrightarrow)$, pruned $(--\boldsymbol{-})$.

community. Another approach was, lupin roots released chitinase and glucanase enzymes enabling to degrade wall cells of fungi, hence killed the microbes. However, mechanisms in limiting soil microbe populations in the kilemo rhizosphere was still well unknown, therefore need a deeper study.

Impacts of fertilizer after pruning on microbes population in the rhizosphere All kinds of fertilizer limited the population of $\mathrm{N}$-fixer, cellulose degrading and $\mathrm{P}$ solubilizing microbes in the soil. This diminution could be observed at almost all the time of observation. Rhizosphere community attenuation happened either to the pruned or not cut trees. However, Figure 4 illustrated that fertilizer application gave advantage only to the population of cellulose degrading microbes on pruned trees This exception was assumed that this microbe got advantages from fertilizing because of this group responsible for decomposing branches (leaves) of pruning that were deposited around the trees. Among the fertilizers, NPK was the most significant to improve the cellulose degrading microbes population. Because this kind of fertilizer rapidly influenced the $\mathrm{C}: \mathrm{N}$ ratio of the litter hence facilitate microbes to decompose.

In this experiment, even fertilizer treatments improved a number of new buds (Figure 2), then increased root exudates released to the rhizosphere (Table 2), conversely, these treatments decreased soil microbe populations in the rhizosphere (Figure 4). Reflecting the former study conducted by Novita (2012) in the same location, fertilizing into 1 year age kilemo rhizosphere caused $\mathrm{pH}$ depletion from 6.7-7.5 (neutral) to 5.6-6.5 (light acidic). 

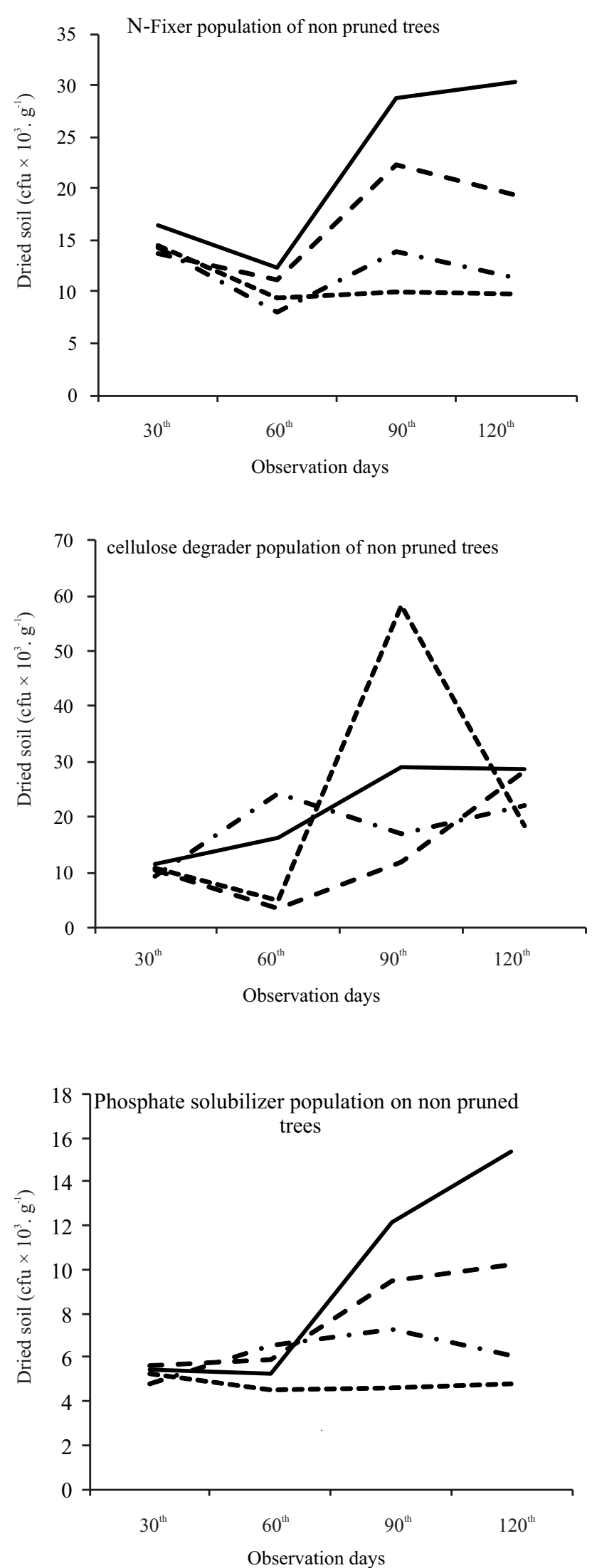
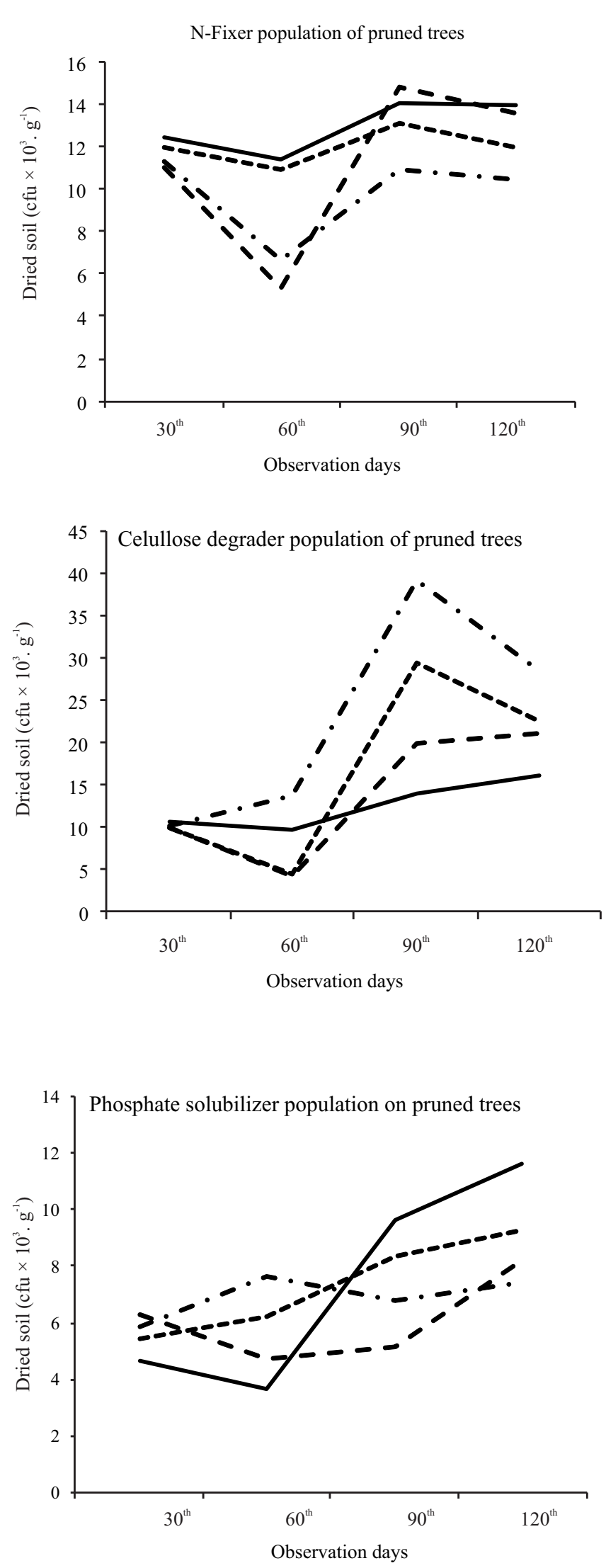

Figure 4 Impacts of fertilizer after pruning on the N-fixer (a \& b), cellulose degrader (c \& d) and phosphate solubilizer (e \& f) population in the kilemo rhizosphere (CFU: colony forming units). Control (-), NPK (- - - ), leaf fertilizer ( -.-.. ), organik(---). 


\section{Conclusion}

It can be concluded that pruning disadvantaged rhizosphere dynamic of kilemo, such as reduced the root exudates consequently depleted the soil microbe populations. Root exudates can be improved by fertilizer application, however, this effort could not recover the rhizosphere community.

\section{Acknowledgement}

Abundant of gratitudes are addressed to R \& D Centre for Forest Productivity for providing the research fund. Thank you very much also expressed to Annisa Nurul Ramadhani for assisting laboratory assessments and to Fahrizal Hazra for kindness advice.

\section{References}

Agrawal N, Choudhaty AS, Sharma MC, Dobhal, MP. 2011. Chemical constituents of plants from the genus of Litsea. Chemistry \& Biodiversity 8:223-243. https://doi.org/ 10.1002/cbdv.200900408.

Alvarez JA, Villagra PE, Villalba R, Debandi G. 2013. Effect of the pruning intensity and tree size on multi-stemmed Prosopsis flexuosa trees in the central Monte, Argentina. Forest Ecology Management 310:857-864. https://doi. org/10.1016/j.foreco.2013.09.033.

Berg G, Steidle N, Eberl A, Zock L, Smalla K. 2002. Plantdependent genotypic and phenotypic diversity of antagonistic rhizobacteria isolated from different verticillium host plats. Applied and Environmental Microbiology 68:3328-3338. https://doi.org/10.1128/ AEM.68.7.3328-3338.2002.

Demoling F, Figueroa D, Baath E. 2007. Comparison of factors limiting bacterial growth in different soils. Soil Biology \& Biochemistry 39:2485-2495. https://doi.org/10. 1016/j.soilbio.2007.05.002.

Dijkstra FA, Cheng W. 2007. Moisture modulates rhizosphere effects on C decomposition in two different soil types. Soil Biology \& Biochemistry 39:2264-2274. https://doi.org/10. 1016/j.soilbio.2007.03.026.

Elsas JVD, Jansson JK, Trevors J. 2006. Modern Soil Ecology. 2nded. Boca Raton: CRC Press.

George TS, Simpsons RJ, Gregory PJ, Daniell TJ. 2009. Extracelluler release of a heterologous phytase of transgenic plants: does manipulation of rhyzosphere biochemistry impact microbial community stucture? FEMS Microbiology Ecology 70:433-445. https://doi.org/ 10.1111/j.1574-6941.2009.00762.x.

Gorissen A, Tietema A, Joosten, NN, Estiarte M, Pen uelas J, Sowerby A, Emmett BA, Beier C. 2004. Climate change affects carbon allocation to the soil in shrublands. Ecosystems 7:650-661. https://doi.org/10.1007/s10021004-0218-4.
Grayston SJ, Campbell CD. 1996. Functional biodiversity of microbial communities in the rhizospheres of hybrid larch (Larix eurolepis) and sitka spruce (Picea sitchensis). Tree Physiology 16:1031-1038. https://doi.org/10.1093/ treephys/16.11-12.1031.

Gregory PJ. 2006. Roots, rhizosphere and soil: The route to a better understanding of soil science. Euroupian Journal of Soil Science 57:2-12. https://doi.org/10.1111/j.13652389.2005.00778.x.

Gunina A, Kuzyakov Y. 2015. Sugars in soil and sweets for microorganisms: Review of origin, content, composition and fate. Soil Biology \& Biochemistry 90:87-100. https://doi.org/10.1016/j.soilbio.2015.07.021.

Heyne K. 1987. Beneficial Plants of Indonesia, second series. Jakarta: Forestry Research and Development Agency.

Hinsinger P. 2001. Bioavailability of soil organic P in the rhizosphere as affected by root-induced chemical changes: A review. Plant and Soil 237:173-195. https://doi.org/10. 1023/A:1013351617532.

Hutsch BW, Augustin J, Merbach W. 2002. Plant rhizodeposition-an important source for carbon turnover in soils. Journal of Plant Nutrition and Soil ScienceZeitschrift Fur Pflanzenernahrung und Bodenkunde 165:397-407. https://doi.org/10.1002/1522-2624(20020 8)165:4<397::AID-JPLN397>3.0.CO;2-C.

Jones DL, Darrah PR. 1994. Role of root derived organic acids in the mobilization of nutrients from the rhizosphere. Plants and Soils 44:1025-1034.

Kadiata BD, Mulongoy K, Mambani B. 1998. Pruning effect on nitrogen nutrient release in the root zone of Albizia lebbeck and Leucaena leucochephala. Biology and Fertility Soils 26:187-193. https://doi.org/10.1007/ s003740050366.

Kandeler E, Kampichler C, Horak O. 1996. Influence of heavy metals on the functional diversity of soil communities. Biology and Fertility Soils 23:299-306. https://doi.org/10. 1007/BF00335958.

Lines-Kelly R. 2005. Defend the rhizosphere and root against pathogenic microorganisms. http://ice.agric.uwa. edu.au/soils/soilhealth. [20 July 2016]

Marschner P, Crowley D, Rengel Z. 2011. Rhizosphere interaction between microorganisms and plants govern iron and phosphorus acquisition along the roots axismodel and research methods. Soil Biology and Biochemistry 43:883-894. https://doi.org/10.1016/ j.soilbio.2011.01.005.

Miah MY, Kanazawa S, Chino M. 1998. Nutrient distribution across wheat rhizosphere with oxamide and ammonium sulfate as N source. Soil Science \& Plant Nutrition 44:579-587. https://doi.org/10.1080/00380768.1998. 10414481 . 
Moritsuka N, Yanai J, Kosaki T. 2013. Effect of application of inorganic and organic fertilizers on the dynamics of soil nutrients in the rhizosphere. Soil Science \& Plant Nutrition 47(1):139-148. https://doi.org/10.1080/00380768. 2001.10408376 .

Neumann G. 2007. Root exudates and nutrients cycling. In: Marschner P, Rengel Z, editors. Nutrients Cyclings in Terrestrial Ecosystem. Berlin: Springer Berlin. https://doi.org/10.1007/978-3-540-68027-7_5.

Novita D. 2012. Impact of fertilizer on chemistry and biology properties of kilemo [thesis]. Bogor: Bogor Agriculture University.

Pansu M, Goutheyrou J. 2003. Handbook of Soil Analysis. New York: Springer.

Sardans J, Penuelas J. 2005. Drought decreases soil enzyme activity in a Mediterranean Quercus ilex L. forest. Soil Biology \& Biochemistry 37:455-461. https://doi.org/10. 1016/j.soilbio.2004.08.004
Sørensen J. 1997. The rhizosphere as a habitat for soil microorganisms. In: Modern soil microbiology. van Elsas JD, Trevors JT, Wellington EMH, editors. New York: Marcel Dekker Inc.

Stark JM, Firestone MK. 1995. Mechanisms for soil moisture effects on activity of nitrifying bacteria. Applied and Environmental Microbiology 61:218-221.

Weiskopf L, Abou-Mansour E, Fromin N, Tomasi N, Santelia D, Edelcot I, Neumann G, Aragno M, Tabacchi R, Martinoia E. 2006. White lupin has developed a complex strategy to limit microbial degradation of secreted citrate required for phosphate acquisition. Plant, Cell \& Environment 29:919-927. https://doi.org/10.1111/j.13653040.2005.01473.x.

Zhang HW, Huang Y, Ye XS, Xu FS. 2010. Analysis of the contribution of acid phosphatase to $\mathrm{P}$ efficiency in Brassica napus under low phosphorus conditions. Science China-Life Sciences 53:709-717. https://doi.org/10.1007/ s11427-010-4008-2. 